\title{
Sigma* and TBP-e radicals obtained by electron capture of four-coordinated phosphorus compounds. A single-crystal ESR study
}

Citation for published version (APA):

Janssen, R. A. J., Sonnemans, M. H. W., \& Buck, H. M. (1986). Sigma* and TBP-e radicals obtained by electron capture of four-coordinated phosphorus compounds. A single-crystal ESR study. Journal of the American Chemical Society, 108(20), 6145-6149. https://doi.org/10.1021/ja00280a006

DOI:

10.1021/ja00280a006

Document status and date:

Published: 01/01/1986

Document Version:

Publisher's PDF, also known as Version of Record (includes final page, issue and volume numbers)

Please check the document version of this publication:

- A submitted manuscript is the version of the article upon submission and before peer-review. There can be important differences between the submitted version and the official published version of record. People interested in the research are advised to contact the author for the final version of the publication, or visit the DOI to the publisher's website.

- The final author version and the galley proof are versions of the publication after peer review.

- The final published version features the final layout of the paper including the volume, issue and page numbers.

Link to publication

\footnotetext{
General rights

- You may freely distribute the URL identifying the publication in the public portal. follow below link for the End User Agreement:

www.tue.nl/taverne

\section{Take down policy}

If you believe that this document breaches copyright please contact us at:

openaccess@tue.nl

providing details and we will investigate your claim.
}

Copyright and moral rights for the publications made accessible in the public portal are retained by the authors and/or other copyright owners and it is a condition of accessing publications that users recognise and abide by the legal requirements associated with these rights.

- Users may download and print one copy of any publication from the public portal for the purpose of private study or research.

- You may not further distribute the material or use it for any profit-making activity or commercial gain

If the publication is distributed under the terms of Article 25fa of the Dutch Copyright Act, indicated by the "Taverne" license above, please 


\title{
$\sigma^{*}$ and TBP-e Radicals Obtained by Electron Capture of Four-Coordinated Phosphorus Compounds. A Single-Crystal ESR Study
}

\author{
René A. J. Janssen, * Max H. W. Sonnemans, and Henk M. Buck \\ Contribution from the Department of Organic Chemistry, Eindhoven University of Technology, \\ Eindhoven, The Netherlands $5600 \mathrm{MB}$. Received January 10, 1985
}

\begin{abstract}
A single-crystal X-band ESR study at $100 \mathrm{~K}$ of X-irradiated dipyrrolidinochlorophosphine sulfide (1) and dimorpholinofluorophosphine sulfide (2) reveals the existence of two phosphoranyl radicals 1a and 2a formed by electron capture at phosphorus. The principal values and direction cosines of the hyperfine and $g$ tensors are determined. It is found that 1a represents a $\sigma^{*}$ structure; i.e., the unpaired electron is located in the antibonding MO of the phosphorus-chlorine bond, whereas 2a possesses a trigonal-bipyramidal (TBP) configuration with fluorine and sulfur in the apical positions and the odd electron in an equatorial position (TBP-e). On annealing, the radicals 1a and 2a dissociate irreversibly by cleavage of the phosphorus-halogen bond and the isostructural thiophosphonyl radicals $\mathbf{1 b}$ and $\mathbf{2 b}$ are obtained. An explanation for the striking difference in electron capture of $\mathbf{1}$ and $\mathbf{2}$ is presented.
\end{abstract}

\section{Introduction}

Phosphoranyl radicals $\left(\dot{\mathrm{PR}}_{4}\right)$ can adopt a variety of molecular geometries and electronic configurations. Most frequently a trigonal-bipyramidal (TBP) structure with the unpaired electron in an equatorial position (TBP-e) is encountered. ${ }^{1-3}$ Alternatively, the odd electron can occupy an apical position of a TBP (TBP-a ${ }^{4}$ or an antibonding orbital between phosphorus and one of the substituents resulting in a three-electron bond $\left(\sigma^{*}\right) .^{5}$ These limiting structures are interconvertible and intermediate structures $\left(C_{s}\right)$ have been established. ${ }^{6}$

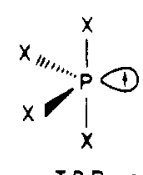

$T B P=e$

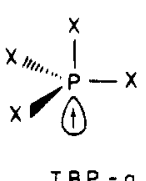

$T B P=0$

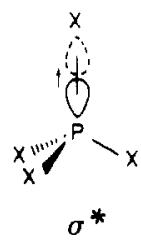

$\sigma$

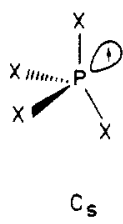

$\mathrm{C}_{\mathbf{S}}$
Phosphoranyl radicals are hypervalent and the singly occupied molecular orbital (SOMO) possesses some antibonding character. The SOMO of these radicals exhibits a large contribution from the valence $3 \mathrm{~s}$ and $3 \mathrm{p}$ orbitals of the central phosphorus atom. The spin density on the substituents is markedly different for the various types of phosphoranyl radicals. For a TBP-e structure the remaining spin density is distributed over the two apical ligands. The delocalization on the two equatorial ligands is small. Experimental data ${ }^{1}$ and quantum chemical calculations ${ }^{7-9}$ reveal that the directions of the phosphorus $3 p$ and valence $p$ orbitals of the apical ligands are nearly perpendicular. The SOMO of a TBP-e phosphoranyl radical is antibonding between phosphorus and the two apical ligands. Quantum chemical calculations ${ }^{7-9}$ on TBP-a radicals suggest large delocalization on the three

(1) Hasegawa, A.; Ohnishi, K.; Sogabe, K.; Miura, M. Mol. Phys. 1975 30,1376

(2) Colussi, A. J.; Morton, J. R.; Preston, K. F. J. Phys. Chem. 1975, 79, 855

(3) Hamerlinck, J. H. H.; Schipper, P.; Buck, H. M. J. Am. Chem. Soc. $1983,105,385$.

(4) Hamerlinck, J. H. H.; Schipper, P.; Buck, H. M. J. Am. Chem. Soc. $1980,102,5679$.

(5) Berclaz, T.; Geofroy, M.; Lucken, E. A. C. Chem. Phys. Lett. 1975, 36,677 .

(6) Berclaz, T.; Geofroy, M.; Lucken, E. A. C. Chem. Phys. Lett. 1979. 62,515

(7) Howell, J. M.; Olsen, J. F. J. Am. Chem. Soc. 1976, 98, 7119

(8) Janssen, R. A. J.; Visser, G. J.; Buck, H. M. J. Am. Chem. Soc. 1984, $106,3429$.

(9) Janssen, R. A. J.; Buck, H. M. J. Mol. Struct. (THEOCHEM) 1984 $110,139$. equatorial substituents and almost none on the apical site. A $\sigma^{*}$ phosphoranyl radical possesses a SOMO with a single nodal plane between phosphorus and the unique substituent. The phosphorus $3 p$ and ligand valence $p$ orbital are parallel. The spin density on the remaining three ligands is small.

The conditions that rule the specific formation of one of the limiting structures are not fully understood. According to Symons ${ }^{10}$ the formation of a $\sigma^{*}$ configuration will be favored when one of the four atoms attached to phosphorus is more electronegative than the other three. To our knowledge three-electron bond phosphoranyl radicals have only been identified when chlorine, bromine, or iodine is linked to phosphorus, ${ }^{11}$ or when the radical possesses a symmetrical phosphorus-phosphorus bond. ${ }^{12,13}$

From the fact that only higher row atoms, with possible d orbital participation, give rise to $\sigma^{*}$ structures, we expected that the electronegativity is not the only factor responsible for the formation of a $\sigma^{*}$ radical

In this study we wish to present a striking difference between the electron capture of dipyrrolidinochlorophosphine sulfide (1) and dimorpholinofluorophosphine sulfide (2) which give rise to phosphoranyl radicals closely resembling the limiting $\sigma^{*}$ and TBP-e configurations.

\section{Experimental Section}

Irradiation and ESR. Single crystals of 1 and $\mathbf{2}$ were mounted on a quartz rod and subsequently sealed in a quartz tube. The crystals were $\mathrm{X}$-irradiated in a glass Dewar vessel containing liquid nitrogen $(77 \mathrm{~K})$ with unfiltered radiation from a $\mathrm{Cu}$ anticathode operating at $40 \mathrm{kV}$ and $20 \mathrm{~mA}$ for approximately $6 \mathrm{~h}$. ESR measurements were performed using a Bruker ER 200D spectrometer operating with a X-band standard cavity. The spectra were recorded digitally using a Bruker Aspect 3000 computer. In a typical run a sweep width of $0.1875 \mathrm{~T}$ was sampled with $4 \mathrm{~K}$ points resulting in a resolution of $0.045 \mathrm{mT}$. Microwave power was set as low as possible, being $2 \mathrm{~mW}$ in most experiments. The crystals were rotated perpendicular to the magnetic field with a single axis goniometer in $10^{\circ}$ steps. Temperature was controlled with the aid of a variable-temperature unit operating between $90 \mathrm{~K}$ and room temperature. ESR parameters were obtained from a second-order analysis of the spectra.

Synthesis. All experiments were done in an atmosphere of dry nitrogen. Solvents were dried by standard methods. ${ }^{1} \mathrm{H}$ NMR spectra were recorded on a Hitatchi Perkin-Elmer R-24B spectrometer. ${ }^{31} \mathrm{P}$ NMR

(10) Symons, M. C. R. Chem. Phys. Lett. 1976, 40, 226

(11) Symons, M. C. R.; Petersen, R. L. J. Chem. Soc., Faraday Trans. $21979,75,210$, and references therein.

(12) Hasegawa, A.; McConnachie, G. D. G.; Symons, M. C. R. J. Chem. Soc., Faraday Trans. 1 1984, 1005, and references therein.

(13) Janssen, R. A. J.; Sonnemans, M. H. W.; Buck, H. M. J. Chem. Phys. 1986, 84,3694 
Table I. Hyperfine Tensors for Radicals $\mathbf{1 a}$ and $\mathbf{1 b}$

\begin{tabular}{|c|c|c|c|c|c|c|c|c|}
\hline \multirow[b]{2}{*}{ radical } & \multirow[b]{2}{*}{ nucleus } & \multirow{2}{*}{$\begin{array}{c}\text { temp } \\
(\mathrm{K})\end{array}$} & \multirow{2}{*}{$\begin{array}{c}\text { total } \\
\text { tensor } \\
(\mathrm{MHz})\end{array}$} & \multirow{2}{*}{$\begin{array}{c}\text { isotropic } \\
\text { part } \\
(\mathrm{MHz})\end{array}$} & \multirow{2}{*}{$\begin{array}{c}\text { dipolar } \\
\text { tensor } \\
(\mathrm{MHz})\end{array}$} & \multicolumn{3}{|c|}{ direction cosines } \\
\hline & & & & & & $x$ & $y$ & $z$ \\
\hline \multirow[t]{2}{*}{$1 \mathbf{a}$} & ${ }^{31} \mathrm{P}$ & 100 & $\begin{array}{l}1822 \\
1851 \\
2282\end{array}$ & 1985 & $\begin{array}{r}-163 \\
-134 \\
297\end{array}$ & $\begin{array}{l}=0.308 \\
=0.668 \\
\pm 0.678\end{array}$ & $\begin{array}{l}0.882 \\
0.065 \\
0.466\end{array}$ & $\begin{array}{r}-0.355 \\
0.742 \\
0.569\end{array}$ \\
\hline & ${ }^{35} \mathrm{Cl}$ & 100 & $\begin{array}{r}57 \\
73 \\
137\end{array}$ & 89 & $\begin{array}{r}-32 \\
-16 \\
48\end{array}$ & $\begin{array}{l}=0.416 \\
\mp 0.873 \\
\pm 0.253\end{array}$ & $\begin{array}{r}0.707 \\
-0.136 \\
0.694\end{array}$ & $\begin{array}{r}-0.572 \\
0.468 \\
0.674\end{array}$ \\
\hline lb & ${ }^{31} \mathrm{P}$ & 140 & $\begin{array}{r}981 \\
1026 \\
1452 \\
\end{array}$ & 1153 & $\begin{array}{r}-172 \\
-127 \\
299\end{array}$ & $\begin{array}{l}\mp 0.593 \\
\pm 0.629 \\
\pm 0.502\end{array}$ & $\begin{array}{l}0.789 \\
0.332 \\
0.517\end{array}$ & $\begin{array}{r}-0.158 \\
-0.703 \\
0.693\end{array}$ \\
\hline
\end{tabular}

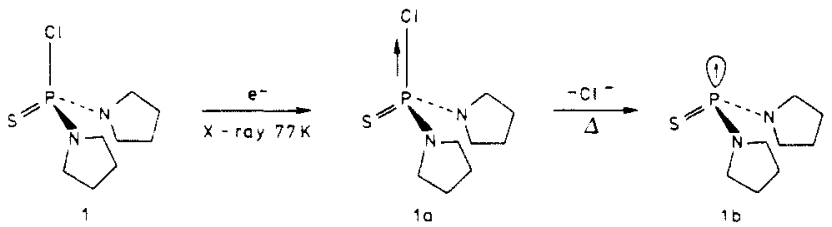

Figure 1. Formation of radicals $1 \mathrm{a}$ and $\mathbf{1 b}$ upon $\mathrm{X}$ irradiation and subsequent annealing.

spectra were recorded on a Bruker HX-90 spectrometer; downfield shifts are quoted positive.

Dipyrrolidinochlorophosphine Sulfide (1). To a stirred solution of 14.2 $\mathrm{g}(0.2 \mathrm{~mol})$ of pyrrolidine in $75 \mathrm{~mL}$ of carbon tetrachloride was added dropwise at $-5{ }^{\circ} \mathrm{C}$ a solution of $8.5 \mathrm{~g}(0.05 \mathrm{~mol})$ of thiophosphoryl chloride $\left(\mathrm{SPCl}_{3}\right)$ in $20 \mathrm{~mL}$ of carbon tetrachloride. After the addition had been completed, the mixture was warmed to $50^{\circ} \mathrm{C}$ for $1 \mathrm{~h}$. Filtration, evaporation of the solvent, and recrystallization from diethyl ether afforded $9.6 \mathrm{~g}(81 \%)$ of $1, \mathrm{mp} 78^{\circ} \mathrm{C}:{ }^{1} \mathrm{H} \mathrm{NMR}\left(\mathrm{CDCl}_{3}\right) \delta 1.80-2.00$ $\left(\mathrm{t}, 4, \mathrm{CH}_{2}\right), 3.06-3.34\left(\mathrm{~m}, 4, \mathrm{NCH}_{2}\right) ;{ }^{31} \mathrm{P} \mathrm{NMR}\left(\mathrm{CDCl}_{3}\right) \delta$ 77.2. Anal. Calcd for $\mathrm{C}_{8} \mathrm{H}_{16} \mathrm{ClN}_{2} \mathrm{PS}$ : C, 40.25; $\mathrm{H}, 6.76 ; \mathrm{N}, 11.73$. Found: $\mathrm{C}, 40.12$; $\mathrm{H}, 6.81 ; \mathrm{N}, 11.92$. Single crystals were obtained by slow evaporation of a diethyl ether solution.

Dimorpholinofluorophosphine Sulfide (2). In analogy to 1, 2 was prepared from $8.7 \mathrm{~g}(0.10 \mathrm{~mol})$ of morpholine in $100 \mathrm{~mL}$ of carbon tetrachloride and $3.8 \mathrm{~g}(0.025 \mathrm{~mol})$ of thiophosphoryl chloride fluoride $\left(\mathrm{SPCl}_{2} \mathrm{~F}\right)^{14}$ in $20 \mathrm{~mL}$ of carbon tetrachloride, yield $4.5 \mathrm{~g}(72 \%)$ of $2, \mathrm{mp}$ $46^{\circ} \mathrm{C}$ : ' $\mathrm{H}$ NMR $\left(\mathrm{CDCl}_{3}\right) \delta 3.19\left(\mathrm{~m}, 4, \mathrm{NCH}_{2}\right), 3.69\left(\mathrm{t}, 4, \mathrm{OCH}_{2}\right) ;{ }^{31} \mathrm{P}$ NMR $\left(\mathrm{CDCl}_{3}\right) \delta 80.0, J_{\mathrm{PF}}=1027 \mathrm{~Hz}$. Anal. Calcd for $\mathrm{C}_{8} \mathrm{H}_{16} \mathrm{FN}_{2} \mathrm{O}_{2} \mathrm{PS}$ : C, 37.79; H, 6.34; N, 11.02. Found: C, 37.74; H, 6.15; N, 10.83. Single crystals were obtained by slow crystallization at $-20^{\circ} \mathrm{C}$ of 2 in tetrahydrofuran (THF)/pentane (12 mL 1:2 THF/pentane for $1 \mathrm{~g}$ of 2).

\section{Results and Assignment}

Dipyrrolidinochlorophosphine Sulfide (1). An X-irradiated single crystal of 1 was studied at $100 \mathrm{~K}$. The ESR spectra show the features of a phosphoranyl radical which can be attributed to the three-electron bond radical 1a (Figure 1). The ESR spectrum of $1 \mathrm{a}$ consists of a ${ }^{31} \mathrm{P}$ doublet with additional hyperfine splitting from one ${ }^{35} \mathrm{Cl}$ or ${ }^{37} \mathrm{Cl}$ nucleus (Figure 2). The singlecrystal ESR spectra of 1a do not show any resolvable additional splitting due to the ${ }^{14} \mathrm{~N}$ nuclei or to the difference in gyromagnetic constant for ${ }^{35} \mathrm{Cl}$ and ${ }^{37} \mathrm{Cl}$. In order to obtain a complete analysis, a flat, regular shaped, single crystal was rotated around three mutual orthogonal axes designated $x, y$, and $z$.

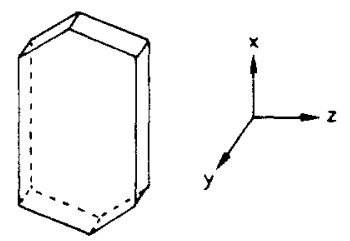

The ESR spectra reveal the existence of two differently oriented radicals. Their spectra coalesce upon rotation around the $x$ axis which appears to be an axis of twofold symmetry. Rotation in the $(x, z)$ and $(y, z)$ planes results in very complex spectra due to overlapping sites. For this reason the interpretation was performed

(14) Roesky, H. W. Chem. Ber. 1967, 100, 1447
Table II. $\mathbf{g}$ Tensor for Radicals $\mathbf{1} \mathbf{a}$ and $\mathbf{1 b}$

\begin{tabular}{ccccc}
\hline & & \multicolumn{3}{c}{ direction cosines } \\
\cline { 3 - 5 } radical & $\mathbf{g}$ & $x$ & $y$ & \multicolumn{1}{c}{$z$} \\
\hline 1a & 1.998 & \pm 0.643 & 0.625 & 0.443 \\
& 2.004 & $\mp 0.656$ & 0.151 & 0.739 \\
& 2.012 & $\mp 0.396$ & 0.766 & -0.507 \\
& & & & \\
1b & 2.000 & $\mp 0.009$ & 0.688 & 0.725 \\
& 2.001 & $\mp 0.808$ & -0.432 & 0.399 \\
& 2.010 & $\mp 0.589$ & 0.583 & -0.560 \\
\hline
\end{tabular}

Table III. Approximate Orbital Spin Densities

\begin{tabular}{ccccc}
\hline radical & nucleus & $\rho_{\mathrm{s}}(\%)$ & $\rho_{\mathrm{p}}(\%)$ & $\mathrm{p} / \mathrm{s}$ \\
\hline $\mathbf{1 a}$ & ${ }^{31} \mathbf{P}$ & 19.5 & 51.9 & 2.66 \\
& ${ }^{35} \mathrm{Cl}$ & 1.9 & 17.1 & 9.00 \\
$\mathbf{1}$ & ${ }^{31} \mathbf{P}$ & 11.3 & 52.3 & 4.63 \\
& ${ }^{14} \mathrm{~N}$ & 2.6 & & \\
& & & & \\
& & & & \\
& ${ }^{31} \mathbf{P}$ & 22.5 & 41.7 & 1.85 \\
& ${ }^{19} \mathrm{~F}$ & 1.9 & 15.0 & 7.90 \\
\hline
\end{tabular}

using computer simulation. The accuracy of the hyperfine coupling (hfc) resulting from these spectra is somewhat less than for the rotation in the $(y, z)$ plane. The principal hyperfine couplings of the two sites are nearly identical $\left( \pm 5 \mathrm{MHz}\right.$ for ${ }^{31} \mathrm{P} ; \pm 0.5 \mathrm{MHz}$ for ${ }^{35} \mathrm{Cl}$ ). Averaged values are compiled in Table I.

On annealing to $240 \mathrm{~K}$ the ESR spectrum of $1 \mathrm{a}$ is irreversibly lost, but signals due to a secondary radical $\mathbf{l b}$ (Figure 1) become apparent. The two orientations of 19 give rise to two orientations of $\mathbf{1 b}$ which coalesce also upon rotation around $x$. Radical $\mathbf{1 b}$ is assigned to a thiophosphonyl radical formed from 1a by dissociation of the phosphorus-chlorine bond. Recooling to $140 \mathrm{~K}$ and subsequent rotation of the crystal afforded the angular dependence of the ${ }^{31} \mathrm{P}$ hfc and their principal values (Table I).

The spectra of $\mathbf{1 b}$ display some additional hyperfine splitting due to the ${ }^{14} \mathrm{~N}$ nuclei. This ${ }^{14} \mathrm{~N}$ hfc, which shows little anisotropy and possesses an average value of approximately $40 \mathrm{MHz}$, is not always resolved and an accurate determination of the principal values was not possible. For the coalesced spectra in the $(y, z)$ plane a remarkably small splitting can be detected for $\mathbf{1 b}$. This splitting is best resolved when the spectra are recorded at $170 \mathrm{~K}$. The multiplet (Figure 3) shows at least 11 lines separated by 0.63 $\mathrm{mT}$. This multiplet structure arises most likely from the coupling of the unpaired electron with two equivalent ${ }^{14} \mathrm{~N}$ nuclei and from four equivalent ${ }^{1} \mathrm{H}$ nuclei where the ${ }^{14} \mathrm{~N}$ hfc is about twice the ${ }^{1} \mathrm{H}$ hfc. Theoretically this combination results in 13 transitions. ${ }^{15}$ The ${ }^{14} \mathrm{~N}$ hfc of $35 \mathrm{MHz}(1.26 \mathrm{mT})$ is in good agreement with the ${ }^{14} \mathrm{~N}$ hfe of the related $\left(\mathrm{Me}_{2} \mathrm{~N}\right)_{2} \mathrm{P}=\mathrm{O}$ phosphonyl radical which is found to be $1.2 \mathrm{mT}^{16}$ The ${ }^{1} \mathrm{H}$ hfc originates presumably from the four hydrogen nuclei on $\mathrm{C}(2)$ and $\mathrm{C}(5)$ of the two pyrrolidine rings which are oriented syn to the SOMO.

The ESR parameters for $\mathbf{1 a}$ and $\mathbf{1 b}$ are collected in Tables I and II. The spin densities in the valence $s$ and $p$ orbitals (re-

(15) Theoretical intensities: 1-4-8-12-16-20-22-20-16-12-8-4-1

(16) Roberts, B. P.; Singh, K. J. J. Organomet. Chem. 1978, 159, 31. 


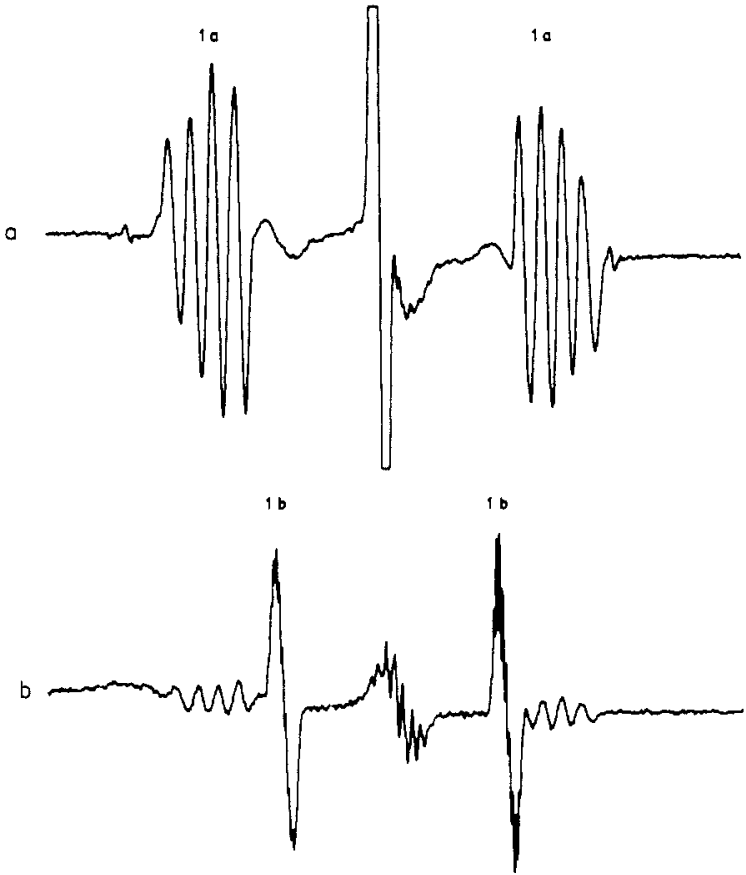

$10 \mathrm{~m} \mathrm{~T}$

Figure 2. Single-crystal ESR spectra of X-irradiated 1. Magnetic field parallel to $(y, z)$ : (a) radical $1 \mathrm{a}$ at $100 \mathrm{~K}$; (b) radical $1 \mathrm{~b}$ at $140 \mathrm{~K}$ after annealing to $240 \mathrm{~K}$.

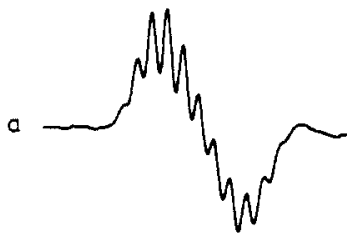

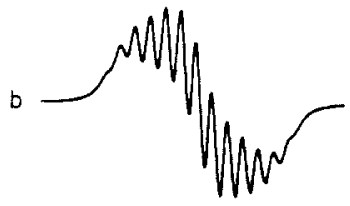

$1 \mathrm{mT}$

Figure 3. High-field multiplet of $1 \mathbf{b}$ at $170 \mathrm{~K}$. Magnetic field parallel to $(y, z)$ : (a) experimental, (b) computer simulation.

spectively $\rho_{\mathrm{s}}$ and $\rho_{\mathrm{p}}$ ) have been estimated from the isotropic and anisotropic contributions to the hyperfine coupling ${ }^{17}$ (Table III). Radical 1a has clearly been formed by electron capture. The unpaired electron occupies an antibonding orbital between phosphorus and chlorine. The spin density is mainly located on phosphorus $(71.4 \%)$ with a p:s ratio of 2.66 . Chlorine contributes for $19.0 \%$ and this spin density is largely confined to the $3 p$ orbital. This distribution is comparable to those of the (alkyl) ${ }_{3} \mathrm{PCl}$ and $\mathrm{Ph}_{3} \dot{\mathrm{PCl}} \sigma^{*}$ phosphoranyl radicals, ${ }^{5,11}$ although in the present case the contribution of chlorine is smaller. The direction cosines in Table I give useful information on the directions of the valence p orbitals contributing to the SOMO. This results from the fact that the direction of the largest principal value is identical with the direction of the $\mathrm{p}$ orbital. For 1a the directions of the ${ }^{31} \mathrm{P}$ and ${ }^{35} \mathrm{Cl}$ tensors are inclined by an angle of $29^{\circ}$. The spin density of the tetrahedral dissociation product $1 \mathrm{~b}$ is predominantly (63.6\%)

(17) Atkins, P. W.; Symons, M. C. R. The Structure of Inorganic Radicals; Elsevier: Amsterdam, 1967.
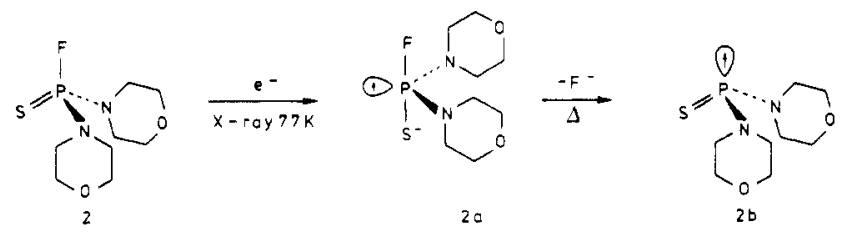

Figure 4. Formation of radicals $\mathbf{2 a}$ and $\mathbf{2 b}$ upon $\mathrm{X}$ irradiation and subsequent annealing.
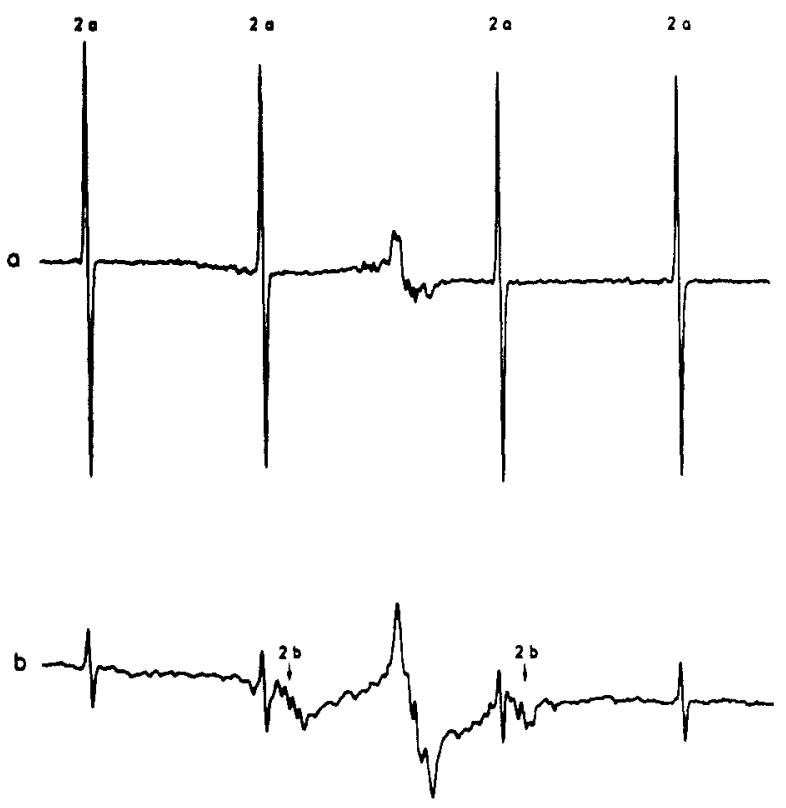

Figure 5. Single-crystal ESR spectra of X-irradiated 2: (a) radical 2a at $100 \mathrm{~K}$; (b) radical $2 \mathrm{~b}$ at $140 \mathrm{~K}$ after annealing to $240 \mathrm{~K}$.

confined to phosphorus with little delocalization on the nitrogen nuclei (each $3 \%$ ). The direction of the ${ }^{31} \mathrm{P}$ anisotropy of $1 \mathrm{~b}$ makes an angle of $12^{\circ}$ with the ${ }^{31} \mathrm{P}$ tensor of $1 \mathrm{a}$ and $17^{\circ}$ with the corresponding ${ }^{35} \mathrm{Cl}$ tensor.

The three principal directions of the largest eigenvalues of 1a and $1 \mathrm{~b}$ lie approximately in one plane (normal vector 0.184 , $\pm 0.672, \mp 0.718$ ). The deviations are small (less than $3^{\circ}$ ). This plane is most likely the molecular plane through the $\mathrm{P}, \mathrm{Cl}$, and $S$ nuclei. If we assume that the direction of the eigenvector associated with the largest eigenvalue lies in the direction of the cleaved phosphorus-chlorine bond, ${ }^{3,18}$ it is possible to relate the molecular geometry with the principal hyperfine coupling directions. Based on the orbital spin densities and directional information we suggest the following structures for $\mathbf{1 a}$ and $\mathbf{1 b}$ :

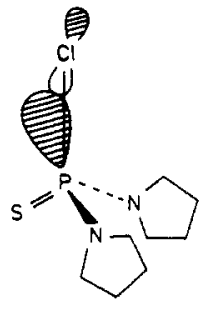

io

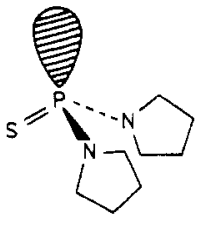

$1 \mathrm{~b}$
Dimorpholinofluorophosphine Sulfide (2). $X$ irradiation of a single crystal of $\mathbf{2}$ generates a phosphoranyl radical 2a (Figure 4), formed by electron capture. The ESR spectrum recorded at $100 \mathrm{~K}$ (Figure 5) exhibits hyperfine coupling to one ${ }^{31} \mathrm{P}$ and one ${ }^{19} \mathrm{~F}$ nucleus. Examination of several single crystals obtained from THF/pentane solutions (see Experimental Section) reveals the existence of two different crystal structures for 2 . One class of

(18) Fouse, G. W.; Bernard, W. A. J. Chem. Phys. 1979, 70, 1667. 
Table IV. Hyperfine Tensors for Radical 2a

\begin{tabular}{|c|c|c|c|c|c|c|c|c|}
\hline \multirow[b]{2}{*}{ radical } & \multirow[b]{2}{*}{ nucleus } & \multirow{2}{*}{$\begin{array}{c}\text { temp } \\
(\mathrm{K})\end{array}$} & \multirow{2}{*}{$\begin{array}{c}\text { total } \\
\text { tensor } \\
(\mathrm{MHz})\end{array}$} & \multirow{2}{*}{$\begin{array}{c}\text { isotropic } \\
\text { part } \\
(\mathrm{MHz})\end{array}$} & \multirow{2}{*}{$\begin{array}{l}\text { dipolar } \\
\text { tensor } \\
(\mathrm{MHz})\end{array}$} & \multicolumn{3}{|c|}{ direction cosines } \\
\hline & & & & & & $x$ & $y$ & $z$ \\
\hline \multirow[t]{2}{*}{$2 \mathbf{a}$} & ${ }^{31} \mathrm{P}$ & 100 & $\begin{array}{l}2140 \\
2214 \\
2535\end{array}$ & 2296 & $\begin{array}{r}-156 \\
-82 \\
239\end{array}$ & $\begin{array}{l}0.534 \\
0.463 \\
0.708\end{array}$ & $\begin{array}{r}-0.455 \\
0.863 \\
-0.221\end{array}$ & $\begin{array}{r}0.713 \\
0.204 \\
-0.671\end{array}$ \\
\hline & ${ }^{19} \mathrm{~F}$ & 100 & $\begin{array}{r}705 \\
709 \\
1390\end{array}$ & 935 & $\begin{array}{r}-230 \\
-226 \\
455\end{array}$ & $\begin{array}{l}0.073 \\
0.870 \\
0.488\end{array}$ & $\begin{array}{r}0.951 \\
0.087 \\
-0.296\end{array}$ & $\begin{array}{r}0.299 \\
-0.486 \\
0.821\end{array}$ \\
\hline
\end{tabular}

Table V. g Tensor for $\mathbf{2 a}$.

\begin{tabular}{ccccc}
\hline & & \multicolumn{3}{c}{ direction cosines } \\
\cline { 3 - 5 } radical & $\mathbf{g}$ & $x$ & $y$ & $z$ \\
\hline $2 \mathbf{2 a}$ & 2.000 & 0.453 & -0.131 & -0.882 \\
& 2.001 & 0.800 & -0.376 & 0.467 \\
& 2.007 & 0.393 & 0.917 & 0.065 \\
\hline
\end{tabular}

single crystals shows two differently oriented radicals after irradiation, resulting in eight lines. The second class reveals only one site (four transitions). In general the single crystals are very fragile and this prevents remounting and recooling. For this reason three different single crystals, with identical habit (class 2), were chosen to obtain an analysis of the principal hyperfine couplings. The single crystals were oriented using a polarization microscope, and three mutual orthogonal reference axes were chosen:

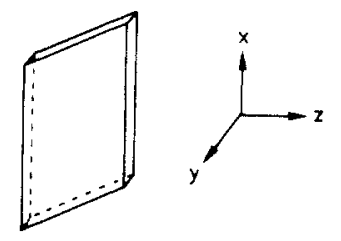

From this type of measurement it is possible to deduce two sets of principal hyperine couplings and principal axes because it is not possible to distinguish between positive and negative senses of rotation about the reference axes. ${ }^{19}$ Additional information to solve this ambiguity was obtained from an independent single-crystal rotation about a fourth axis in the $(x, y)$ plane. The principal values of the hyperfine and $\mathbf{g}$ tensors are compiled in Tables IV and V together with the corresponding direction cosines.

On annealing to $190 \mathrm{~K}$ the features of radical $2 \mathrm{a}$ start to disappear from the ESR spectrum and, on increasing the spectrometers receiver gain, weak signals attributable to $\mathbf{2 b}$ (Figures 4 and 5) can be detected. A complete analysis of these signals proved to be impracticable because of their weak intensity. However, the powder spectra of $\mathbf{1 b}$ and $\mathbf{2 b}$ are virtually identical and we suggest similar hyperfine couplings.

The orbital populations (Table III) which can be derived from the hyperfine interactions indicate that for $2 \mathrm{a}$ the main part of the spin density is confined to phosphorus $\left(\rho_{\mathrm{s}}=22.5 \%\right.$ and $\rho_{\mathrm{p}}=$ $41.7 \%$ ). The fluorine atom contributes for a total of $16.9 \%$ to the SOMO, largely with the $2 \mathrm{p}$ orbital. The magnitudes of the isotropic and anisotropic ${ }^{19} \mathrm{~F}$ hfcs are comparable to the apical ${ }^{19} \mathrm{~F}$ hfcs of the TBP-e $\dot{P F}_{4}$ radical $\left(A_{\text {iso }}=857 \mathrm{MHz} ; 2 B=386\right.$ $\mathrm{MHz}){ }^{1}$ The angle between the principal directions of the anisotropies of phosphorus and fluorine is $82^{\circ}$ (or $180^{\circ}-82^{\circ}=98^{\circ}$ ). This nearly perpendicular orientation leads to the assignment of a TBP-e configuration for $2 a$. The fluorine nucleus possesses an apical position in the TBP structure and the unpaired electron resides as a fifth ligand in an equatorial position.

The nature of the second apical ligand, in principle nitrogen or sulfur, cannot be derived directly from the ESR spectra. We nevertheless suggest that the sulfur nucleus occupies the second apical site. Two facts support this assignment. First, no ${ }^{14} \mathrm{~N}$ hfc is observed whereas an apically located ${ }^{14} \mathrm{~N}$ nucleus normally exhibits a hyperfine coupling of approximately $70 \mathrm{MHz}^{20,21}$ The

(19) Schonland, D. S. Proc. Phys. Soc. London, Ser. A 1959, 73, 788.
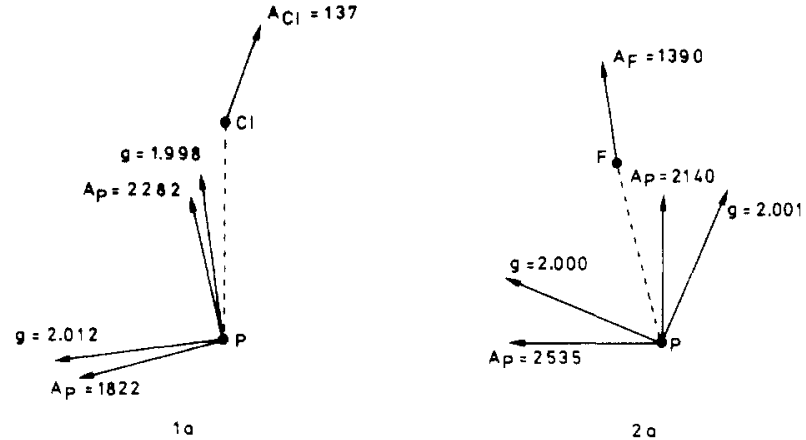

Figure 6. Schematic representation of the principal directions for 1a and 2 a.

second argument is based on symmetry considerations. The precursor molecule possesses $C_{s}$ symmetry. Upon the formation of a TBP-e phosphoranyl radical with apical ${ }^{19} \mathrm{~F}$ and ${ }^{14} \mathrm{~N}$ nuclei this symmetry would be lost. In that case the ESR spectrum will show two differently oriented radicals because both morpholino groups have an equal chance to occupy the apical position. The observation of only one site is in accordance with our assignment of an apical sulfur nucleus.

The exact molecular geometry of $2 \mathbf{a}$ cannot be determined experimentally. Upon electron capture the original tetrahedral geometry will be deformed toward a TBP configuration by an enlargement of the angle between the P-F and P-S bonds. We suggest the following structure:

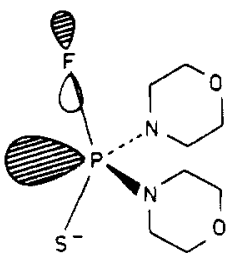

\section{Discussion}

From this study it is clear that the structure of a phosphoranyl radical strongly depends on the nature of the ligands.

Radical 1a represents a near $\sigma^{*}$ structure in which the extra electron occupies an antibonding orbital between phosphorus and chlorine. The original tetrahedral geometry of precursor 1 will be preserved upon electron capture although the phosphoruschlorine bond will elongate. The weakening of the three-electron bond, because of its partial antibonding character, is nicely demonstrated by the observed dissociation of $1 \mathbf{a}$ into $\mathbf{1 b}$ on annealing. The small angle of $12^{\circ}$ between the principal directions of the ${ }^{31} \mathbf{P}$ hfes of $\mathbf{1 a}$ and $\mathbf{1 b}$ in the single crystal indicates the near in-line mode of this process.

Radical 2a possesses a TBP-e structure with fluorine and sulfur in apical positions. The exact contribution of the sulfur nucleus to the SOMO remains unknown because the ${ }^{32} \mathrm{~S}$ isotope possesses no spin angular momentum. Table III reveals that $18.9 \%$ of the unpaired electron density could not be detected. This might be

(20) Hamerlinck, J. H. H.; Hermkens, P. H. H.; Schipper, P.; Buck, H. M. J. Chem. Soc, Chem. Commun. 1981, 358.

(21) Giles, J. R. M.; Roberts, B. P. J. Chem. Soc., Perkin Trans. 2 1981, 


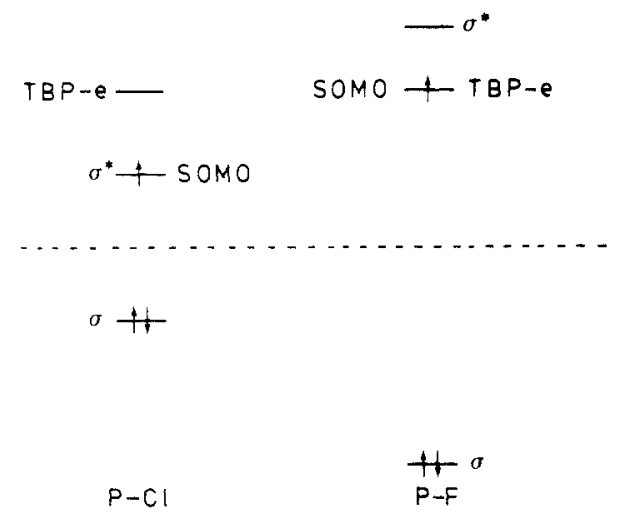

Figure 7. Orbital diagram for the formation of $\sigma^{*}$ and TBP-e structures in $1 \mathbf{a}$ and $2 a$, respectively.

an indication of the delocalization on sulfur. The apical location of the sulfur substituent in a TBP-e phosphoranyl radical is unusual but has also been found in electron capture radicals of tetramethyland tetraethyldiphosphine disulfides. ${ }^{13}$

The $C_{s}$ symmetry of the radicals $1 \mathrm{a}$ and $2 \mathrm{a}$ forces the principal direction of one $g$ value and one ${ }^{31} \mathrm{P}$ hfc to be parallel. For 1a these parallel principal values are $g=2.004$ and $A_{\mathrm{P}}=1851 \mathrm{MHz}$, whereas for $2 \mathrm{a} g=2.004$ and $A_{\mathrm{P}}=2214 \mathrm{MHz}$ are nearly aligned. The remaining principal directions (Figure 6) are located in one plane. Figure 6 reveals that the direction of the largest $A_{\mathrm{p}}$ is close to the minimum of $g$. This is expected because it is the direction of the contributing phosphorus $3 p$ orbital.

An attempt to obtain a quantum chemical description of the radicals 1a and 2a was not successful. Ab initio calculations on STO-3G and 4-31G SCF levels, using methods described before, 8,9 did not reveal stable geometries for model species of $\mathbf{1 a}$ and $\mathbf{2 a}$ in which the pyrrolidino and morpholino groups are replaced by $\mathrm{NH}_{2}$ groups. For both radicals gradient optimization leads to dissociation of the phosphorus-halogen bond.

The observed difference in radical structure can be rationalized on basis of the nature of the halogen substituents and the intrinsic properties of the phosphorus-halogen bonds. According to Giles and Roberts, ${ }^{21}$ the tendency for a substituent (A) to occupy an apical position in a TBP is determined by the electron affinity $\left(E_{\mathrm{A}}\right)$ of $\mathrm{A}^{-}$and the average homolytic bond dissociation enthalpy $(\bar{D}(\mathrm{P}-\mathrm{A}))$. An increase of $E_{\mathrm{A}}$ and decrease of $\bar{D}(\mathrm{P}-\mathrm{A})$ will lead to a higher apicophilicity. Comparison of these values ${ }^{22,23}$ for

(22) Bartmess, J. E.; Scott, J. A.; Mclver, R. T. J. Am. Chem. Soc. 1979, $10 l, 6046$.

(23) Bentrude, W. G. In Free Radicals, Kochi, J. K., Ed.; Wiley-Interscience: New York, 1973; pp 595-663. fluorine $\left(E_{\mathrm{A}}=328 \mathrm{~kJ} \mathrm{~mol}^{-1}, \bar{D}(\mathrm{P}-\mathrm{A})=490 \mathrm{~kJ} \mathrm{~mol}^{-1}\right)$ and chlorine $\left(E_{\mathrm{A}}=349 \mathrm{~kJ} \mathrm{~mol}^{-1}, \bar{D}(\mathrm{P}-\mathrm{A})=323 \mathrm{~kJ} \mathrm{~mol}^{-1}\right)$ reveals a larger apicophilicity for chlorine. If the tendency for a substituent to occupy an apical position is appreciably larger than for the other three, a $\sigma^{*}$ structure will be preferred. If, however, the apicophilicity is more or less equal for two substituents a TBP-e configuration can be expected.

Correspondingly, an explanation for the formation of the $\sigma^{*}$ and TBP-e structures can be derived from a qualitative description of the MO scheme (Figure 7). The P-F bond is approximately $167 \mathrm{~kJ} \mathrm{~mol}^{-1}$ more stable than the $\mathrm{P}-\mathrm{Cl}$ bond. Consequently, the $\mathrm{P}-\mathrm{F} \sigma$ MO lies below the P-Cl $\sigma^{*} \mathrm{MO}$. The LUMO's of the precursors 1 and 2 will be singly occupied upon electron capture. For compound 1 the energy gap between the $\mathrm{P}-\mathrm{Cl} \sigma$ and $\sigma^{*}$ MO's will be smaller than for the P-F bond in compound 2 . It is therefore conceivable that the LUMO of 2 is not the $\sigma^{*}$ MO but a TBP-e like orbital. Apparently the TBP-e and $\sigma^{*}$ MO's are interconverted for the two compounds. Since both orbitals possess the same type of symmetry ( $\mathrm{A}^{\prime}$ in $C_{s}$ point group), some mixing will occur, resulting in the observed deviations from pure $\sigma^{*}$ and pure TBP-e configurations.

Similar arguments have been put forward by Clark in ab initio studies on phosphorus and chlorine $\sigma^{*}$ radical cations, ${ }^{24}$ and on $C_{3 v}$ and $C_{s}$ silyl halide anions. ${ }^{25,26}$ An important factor, determining the stability of a two-center, three-electron bond, is the energy gap between the interacting orbitals of the two molecular groups that form the $\sigma^{*}$ bond. In case the two orbitals are (nearly) degenerated, a stable $\sigma^{*}$ radical can be expected. TBP configurations become more favorable for large values of the energy gap.

Acknowledgment. This investigation has been supported by the Netherlands Foundation for Chemical Research (SON) with financial aid from the Netherlands Organization for the Advancement of Pure Research (ZWO). We thank Olav M. Aagaard, Frank M.J. van den Berghe, Wim A.M. Bruekers, Ruud M. van Brunschot, and Roland G.M. de Bruyn for their enthusiastic collaboration in parts of this project.

Registry No. 1a, 103884-66-8; 1b, 103904-08-1; 2, 103884-65-7; 2a, 103884-67-9; 2b, 103884-68-0; $\mathrm{SPCl}_{2} \mathrm{~F}, 2523-93-5 ; \mathrm{SPCl}_{3}, 3982-91-0$; pyrrolidine, 123-75-1; morpholine, 110-91-8.

Supplementary Material Available: Graphical representation of the angular variations of the ${ }^{31} \mathrm{P},{ }^{35} \mathrm{Cl}$, and ${ }^{19} \mathrm{~F}$ hfes for radicals $\mathbf{1 a}, \mathbf{1 b}$, and $2 \mathrm{a}$ ( 6 pages). Ordering information is given on any current masthead page.

(24) Clark, T. J. Comput. Chem. 1983, 4, 104.

(25) Clark, T. J. Chem. Soc, Chem. Commun. 1981, 515

(26) Clark, T. J. Chem. Soc., Perkin Trans. 1982, 1267. 